\title{
Farklı yüzey işlemlerinden sonra zirkonyum seramiğinde yüzey pürüzlülüğünün değerlendirilmesi
}

\author{
Faik Tuğut(0000-0002-6323-407X) ${ }^{\alpha}$, Ümit Güney(0000-0003-2848-8207) ${ }^{\beta}$
}

Selcuk Dent J, 2020; 7: 163-169 (Doi: 10.15311/selcukdentj.433704)

Başvuru Tarihi: 13 Haziran 2018 Yayına Kabul Tarihi: 02 Nisan 2019

\author{
öz \\ Farklı yüzey işlemlerinden sonra zirkonyum seramiğinde \\ yüzey pürüzlülüğünün değerlendirilmesi
}

Amaç: Bu çalışmanın amacı sinterizasyon öncesi ve sinterizasyon sonrası zirkonyum oksit esaslı seramikler üzerine uygulanan farklı yüzey işlemlerinin yüzey pürüzlülüğüne olan etkisini araştırmaktır.

Gereç ve Yöntemler: Calıșmada 150 adet disk șeklinde örnek, bilgisayar destekli tasarım ve üretim yöntemiyle hazırlandı. Örnekler; kontrol grubu, kumlama, Er-YAG lazer, Nd-YAG lazer, ErYAG lazer + Kumlama, Nd-YAG lazer + kumlama, ince ve kalın grenli frez olmak üzere 8 gruba ayrıldı ( n:10). Örneklerin yarısına sinterizasyon öncesi yüzey işlemleri uygulandı. Daha sonra sinterlendi. Diğer yarısına sinterizasyon sonrası yüzey işlemi uygulandı. Kontrol grubuna herhangi bir yüzey işlemi uygulanmadı. Örneklerin yüzey pürüzlülüğü profilometre cihazı ile ölçüldü ve yüzeylerinde olan değişiklikler taramalı elektron mikroskobu ile incelendi.

Bulgular: Çalışmada elde edilen veriler Varyans analizi, Tukey testi ve eşler arası önemlilik testi ile analiz edildi $(p=0,05)$. Sinterizasyon öncesi uygulanan yüzey işlemlerinin frez uygulanan gruplar hariç yüzey pürüzlülüğünü istatistiksel olarak anlamlı derecede arttırdığı görüldü $(p<0,05)$. Sinterizasyon sonrası uygulanan yüzey işlemlerinde ise ince grenli frez haricindeki tüm grupların yüzey pürüzlülüğünü istatistiksel olarak anlamlı derecede arttırdığı gözlendi $(p<0,05)$. Sinterizasyon öncesi yüzey uygulamaları sinterizasyon sonrası uygulamalarına göre daha etkili bulundu.

Sonuç: Çalışmada sinterizasyon öncesi uygulanan tüm yüzey işlemleri ve özellikle Er-YAG lazer+ kumlamanın pürüzlülük değerini arttırdığı gözlenmiştir.

\section{ANAHTAR KELIMELER}

Frez, kumlama, lazer, yüzey pürüzlülük, zirkonyum oksit

Diş hekimliğinde uzun süredir kullanılan metal destekli porselenlere alternatif olarak mekanik özelliklerinin geliştirilmesi, estetik üstünlükleri ve biyouyumluluktan dolayı tam seramik restorasyonlar daha fazla talep görmeye başlamıştır. ${ }^{1} \mathrm{Bu}$ artan talep yoğunlukla zirkonyum oksit ve alüminyum oksit gibi mekanik özellikleri geliştirilmiş tam seramik materyallerin gelişmesine yol açmıştır. ${ }^{2}$ Zirkonyum oksit yüksek dayanıklıık, biyouyumluluk, iyi kimyasal kararlıık ve
ABSTRACT

Assesment of surface roughness of zirconia ceramic after different surface treatments

Background: The aim of this study is to investigate the effect of different surface treatments on the surface roughness of zirconium oxide based ceramics before and after sintering

Material and Method: In this study, 150 disk shaped samples were prepared in computer aided design and manufacture method. Samples were divided into 8 groups as control group, Er-YAG laser, Nd-YAG laser, Er-YAG+sandblasting, Nd-YAG laser+sandblasting, fine diamond burs, coarse diamond burs ( $\mathrm{n}$ : 10). Half of the samples were treated before sintering. Then sintered. The others were treated after the sintering procedures. No treathments were performed in control group. The surface roughness of the samples was measured by a profilometer and the changes in their surface were examined by scanning electron microscopy.

Results: Data were analyzed by variance analysis, Tukey test and parity significance test in the study $(p=0,05)$. It was observed that all the groups except the burs groups increased the surface roughness statistically significant in the surface treatments before the sintering $(p<0,05)$. It was observed that all the groups except the fine grained burs increased the surface roughness statistically significant in the surface treatments after the sintering $(p<0,05)$. Surface applications before sintering were more effective than applications of after sintering.

Conclusion: All the surface treatments applied before sintering and especially the roughness value of Er-YAG laser + sandblasting were greatly increased.

\section{KEYWORDS}

Bur, sandblasting, laser, surface roughness, zirconium oxide

doğal görünüm özelliklerinden dolayı ideal bir dental materyal olarak kabul edilmiştir. ${ }^{3,4}$ Ayrıca dayanıklıık ve yüksek kırılma direncine sahip olması ve uzun protez yapımına izin vermesi sebebiyle son dönemde popülarite kazanmaya başlamıştır. ${ }^{4,5}$

Adeziv sistemin gelişmesiyle beraber daha stabil ve dayanıklı restorasyonların yapılması için bir çok araştırmacı $\mathrm{ZrO}_{2}$ ( Zirkonyum oksit) yüzeyinde mikro

\footnotetext{
${ }^{\alpha}$ Cumhuriyet Üniversitesi Diş Hekimliği Fakültesi Protetik Diş Tedavisi Anabilim Dalı, Sivas

$\beta$ Serbest Diş Hekimi, Ordu
} 
tutucu alan elde etmek, yüzey alanını artırmak için farklı yüzey işlemleri denemişlerdir. ${ }^{4,6} \mathrm{Bu}$ yüzey işlemleri hem zirkonya ile rezinlerin hem de zirkonya ile seramiklerin arasındaki bağlantıyı ve restorasyonun uzun süre başarılı şekilde kullanılmasını sağlamıştır. Zirkonyanın camsı faz yapısında olması ve silika içermediğinden, asitlemeyle yüzeyinin pürüzlendirilmesinde ve silanla kimyasal bağlantı elde edilmesinde sorunlar oluşturmuştur. Zirkonyanın simantasyonunda karşılaşılan zorluklar nedeniyle alternatif bağlantı yöntemleri uygulanmaya başlanılmıştır. ${ }^{7,8}$ Araştırmacılar farklı uygulamaların zirkonyada yüzey pürüzlülüğünü arttırdığını belirtmişlerdir. Bu uygulamalar Alüminyum oksit $\left(\mathrm{Al}_{2} \mathrm{O}_{3}\right)$ ile kumlama ${ }^{9,10,11}$, frez ile aşındırma ${ }^{12}$, lazer $^{4,9,10,12}$ veya bunların kombinasyonu şeklindedir.

Kumlama, zirkonya alt yapı ile üst yapı porseleni arasındaki ve alt yapı ile rezin siman arasındaki yüzeyde pürüzlülük sağlayarak mekanik bağlantının arttırılması için kullanılmıştır. Ayrıca zirkonyada alt yapı-üst yapı bağlantı dayanımını da arttırdığı belirtilmiştir. ${ }^{13}$

Bir diğer yüzey pürüzlendirme yöntemi de lazer uygulamadır. Son zamanlarda özellikle diş materyalleri olan seramiklerin yüzey işlemlerinin araştırılmasında kullanılmıştır. ${ }^{14,15}$ Erbium: yttrium-aluminium-garnet (Er:YAG) and Neodmium: yttrium-aluminium-garnet (Nd:YAG) lazerler bu amaç için kullanılmıştır. ${ }^{14,15}$ $\mathrm{Nd}$ :YAG lazerlerin, yumuşak doku lazeri olmalarının yanında çeşitli araştırmalarda seramik ve $\mathrm{ZrO}_{2}$ yüzey pürüzlendirmede de etkili olduğu bildirilmiştir. Neodmium katılmış yttrium-aluminium-garnet kristali (Nd:YAG) lazer, fiber optik yolla doku ile kontak halinde kullanılan, diş hekimliği uygulamalarında sıklıkla yer alan bir lazer çeşitidir. ${ }^{10}$ Erbium:yitrium-aluminiumgarnet (Er:YAG) lazer ise kavite preparasyonu, çürüklerin kaldırılması gibi farklı klinik uygulamalarda kullanılmıştır. ${ }^{16,17}$

Literatürlerde sinterizasyon sonrası yapılan yüzey işlemlerinin $\mathrm{ZrO}_{2}$ yapısında monoklinik faz içeriğini arttırarak yapıya zarar verdiği ve kırık riskini artırdığı rapor edilmiştir. ${ }^{18,19} \mathrm{Bu}$ sebeple araştırmacılar $\mathrm{ZrO}_{2}$ yüzeyine sinterizasyon öncesi yapılan yüzey işlemleri sonrası tetragonal faz içeriğinin fazla olması ile $\mathrm{ZrO}_{2}$ 'in mekanik özelliklerinin geliştirilebilmesi ve sinterizasyon sonrasına göre daha düzensiz ve pürüzlü bir alan elde edilebileceği gibi avantajlarının olduğunu savunmuşlardır. ${ }^{10,20} \mathrm{Bu}$ nedenle bu çalışmada $\mathrm{ZrO}_{2}$ yüzeyinde sinterizasyon öncesi yüzey işlemleri ile sinterizasyon sonrası yüzey işlemlerinin etkileri beraber değerlendirilecektir. Bu çalışmanın amacı sinterizasyon öncesi ve sinterizasyon sonrası zirkonyum oksit esaslı seramikler üzerine uygulanan farklı yüzey işlemlerinin yüzey pürülülüğüne olan etkisini araştırmaktır. Çalışmamızda sinterizasyon öncesi ve sonrası tüm yüzey işlemleri yüzey pürüzlülüğünü arttırır hipotezi test edilmektedir.

\section{GEREÇ VE YÖNTEM}

Çalışmada yarı sinterize zirkonyum oksit esaslı bloklar (Noritake Dental Inc, Japonya) kullanılmıştır. Bu bloklardan toplam 150 adet disk şeklinde çapı $15 \mathrm{~mm}$ ve kalınlığı 1,3 mm olan örnekler elde edilmiştir. Kontrol grubu örnekleri haricindeki örneklerin yarısı elde edildikten sonra, kalan örnekler ise yüzey işlemi uygulandıktan sonra üreticinin talimatlarına göre sinterlenmiştir. Sinterizasyon işlemi, sinterizasyon fırınında (Protherm Furnaces, İstanbul, Türkiye) oda sıcaklığından $1375^{\circ} \mathrm{C}$ 'ye gelip tekrar oda sıcaklığına gelmesi sağlanarak toplam 8 saatte tamamlanmıştır. İki ana grup oluşturulduktan sonra örneklere farklı yüzey işlemleri uygulayarak 8 alt grup $(n=10)$ oluşturulmuştur.

Kontrol(C): Yüzey işlemi uygulanmamıştır.

Kumlama (K): Kumlama cihazıyla (Blastmate II; Ney, Yucaipa, CA, Amerika), örnek yüzeylerine $110 \mu \mathrm{m} \mathrm{Al}_{2} \mathrm{O}_{3}$ partikülleri $0,5 \mathrm{MPa}$ basınçla $10 \mathrm{~mm}$ uzaklıktan 15 saniye boyunca uygulanmıştır. Daha sonra örnekler akan su altında yıkanmış ve kurutulmuştur.

Er:YAG Lazer (E): Örnek yüzeyleri optik fiber taşıma sistemi ile 20 saniye taranarak uygulanmıştır. Uygulama mesafesi $10 \mathrm{~mm}$ olarak ayarlanmıştır. Işın ayarları 150 $\mathrm{mJ}, 1,5 \mathrm{~W}$ ve $10 \mathrm{~Hz}$ enerji değerlerine getirilerek Er:YAG lazer (Smart 2940D Deka Laser, Floransa, Italya) uygulaması yapılmıştır.

Nd:YAG Lazer ( $\mathbf{N})$ : Örnek yüzeylerine optik fiber taşıma sistemi ile $10 \mathrm{~mm}$ uzaklıktan 20 saniye boyunca Nd:YAG lazer (Smarty A10 Deka Laser, Floransa, Italya) uygulanmıştır. Işın ayarları $100 \mathrm{~mJ}, 1 \mathrm{~W}, 10 \mathrm{~Hz}$ enerjiye getirilmiştir.

Er:YAG Lazer ve Kumlama (EK): Örnekler 150 mJ, 1,5 W, $10 \mathrm{~Hz}$ enerji ile $10 \mathrm{~mm}$ uzaklıktan 20 saniye boyunca lazer ile ışınlanmıştır. Daha sonra örnekler akan su altında yıkanmış ve kurutulmuştur. Her bir lazer uygulanan örnekler yüzeyine $110 \mu \mathrm{m} \mathrm{Al}_{2} \mathrm{O}_{3}$ partikülleri 0,5 MPa basınçla $10 \mathrm{~mm}$ uzaklıktan 15 saniye boyunca uygulanmıştır.

Nd:YAG Lazer ve Kumlama (NK): Örnekler 100 mJ, 1 W, $10 \mathrm{~Hz}$ enerji ile $10 \mathrm{~mm}$ uzaklıktan 20 saniye boyunca lazer ile ışınlanmıştır. Daha sonra örnekler akan su altında yıkanmış ve kurutulmuştur. Her bir lazer uygulanan örnekler yüzeyine $110 \mu \mathrm{m} \mathrm{Al}_{2} \mathrm{O}_{3}$ partikülleri $0,5 \mathrm{MPa}$ basınçla $10 \mathrm{~mm}$ uzaklıktan 15 saniye boyunca uygulanmıştır.

Ince Grenli Frez (IG): Örneklerin aşındırılması için gren boyutu $50 \mu \mathrm{m}$ olan elmas frezler (Meisinger, Hansemannstr, Neuss, Almanya) tercih edilmiştir. Frez piyasemene takılıp, dakikada dönme hızı 20000'e ayarlanmıştır. Aşındırma işlemi ile birlikte örnek yüzeyinden $0,1 \mathrm{~mm}$ materyal kaldırılmıştır. Dijital kumpas ile kalınlıkları ölçülmüştür. 
Kalın Grenli Frez (KG): Örneklerin aşındırılması için gren boyutu $200 \mu \mathrm{m}$ olan elmas frezler (Meisinger, Hansemannstr, Neuss, Almanya) kullanılmıştır. Frez piyasemene takılıp, dakikada dönme hızı 20000'e ayarlanmıştır. Aşındırma işlemi ile birlikte örnek yüzeyinden $0,1 \mathrm{~mm}$ materyal kaldırıımıştır. Dijital kumpas ile kalınlıkları ölçülmüştür.

Bu yüzey işlemleri bir gruba sinterizasyon öncesi (SÖ) uygulanıp sinterlenmiştir. Diğer gruba da sinterizasyon sonrası(SS) uygulanıp yüzey işlemleri tamamlanmıştır. Yüzey işlemlerinden sonra tüm örnekler ultrasonik banyoda 3 dakika boyunca temizlenmiştir. Örnekler 24 saat boyunca $37^{\circ} \mathrm{C}$ de su banyosunda bekletilmiştir.

\section{Yüzey pürüzlülük değerlendirilmesi}

Her bir örneğin yüzey pürüzlülük değeri $(R a, \mu m)$ bir profilometre cihazı (Mitutoyo Surftest/ SJ-301, Tokyo, Japonya) ile yapılmıştır. Çalışmada aletin ölçüm uzunluğu $5.5 \mathrm{~mm}$ olarak ayarlanmıştır. Örnek üzerinde 3 farklı yerden ölçüm yapılmıştır. Ölçümlerin aritmetik ortalaması alınmıştır. Her örneğin ortalama yüzey pürüzlülük $(R a, \mu m)$ değerleri kaydedilmiştir. Yüzey işlemleri sonrası $\mathrm{ZrO}_{2}{ }^{\prime}$ in yüzey morfolojik değişiklikleri, taramalı elektron mikroskop (SEM) (LeO 440-7060, İngiltere) ile değerlendirilmiştir.

Elde edilen veriler SPSS 22.0 (SPSS Inc, Chicago, Amerika) programına yüklenerek verilerin değerlendirilmesinde parametrik test varsayımları yerine getirildiğinden Varyans analizi, Tukey testi ve eşler arası önemlilik testi uygulanmıştır. Yanılma düzeyi 0,05 olarak alınmıştır.

\section{BULGULAR}

Sinterizasyon öncesi (SÖ) ve sinterizasyon sonrası (SS) yüzey işlemi uygulanan zirkonyanın yüzey pürüzlülük ortalama ve standart sapma değerleri Tablo 1 ve Şekil 1'de gösterilmiştir. Sinterizasyon öncesi uygulanan gruplar ve sinterizasyon sonrası uygulanan grupların hepsinde kontrol grubuna göre pürüzlülük değerlerinin arttığı görülmüştür. Hem sinterizasyon öncesi hem de sinterizasyon sonrası uygulanan yüzey işlemlerinde Er:YAG Lazer + kumlama (SÖ:4,20 $\pm 0,40$, SS:4,06 $\pm 0,45$ ) işleminin en yüksek pürüzlülük değerine sahip olduğu görülmüştür. Kontrol grubuna göre istatistiksel olarak anlamlı bulunmuştur $(P<0,05)$. SÖ uygulanan ince grenli frez ve kalın grenli frez grupları kontrol grubuna $(0,65 \pm 0,11)$ yakın değerler göstermiştir. Her iki gruptaki yüzey işlemlerinin kendi aralarında kıyaslandığında (Er:YAG Lazer + kumlama) işlemi haricindeki tüm yüzey işlemlerinin SÖ ve SS'deki gruplarda istatistiksel olarak anlamlı olduğu görülmüştür $(P<0,05)$. Frez ile aşındırma hariç tüm yüzey işlemleri kontrol grubuna göre SÖ grupta pürüzlülük değeri bakımından yüksek ve anlamlı bulunmuştur $(P<0,05)$. SEM incelemesinde Er:YAG Lazer+ kumlama ile Er:YAG lazer gruplarında derin ve pürüzlü yapılar, sivri, keskin kenarlar daha belirgin olduğu görülür iken Nd:YAG Lazer, ince grenli frez ve kalın grenli frez grubunda yüzeyel ve dar çizgisel oluklar görülmüştür. Ayrıca SÖ yapılan yüzey uygulamalarında oluşan derin ve pürüzlü yapılar, çukur ve keskin kenarlar sinterizasyon sonrası frez ile aşındırma grubu haricindeki diğer gruptakilere oranla daha belirgin olarak SEM incelemesinde tespit edilmiştir (Resim 1, Resim 2).

Tablo 1.

Zirkonya alt yapısının sinterizasyon öncesi ve sonrası yüzey pürüzlük değerleri $(R a, \mu \mathrm{m})$

\begin{tabular}{|c|c|c|c|}
\hline Gruplar & $\begin{array}{l}\text { Sinterizasyon Öncesi } \\
X \pm \text { Ss }(R a, \mu \mathrm{m})\end{array}$ & $\begin{array}{l}\text { Sinterizasyon Sonrası } \\
X \pm \text { Ss }(R a, \mu m)\end{array}$ & \\
\hline Kontrol & $0,65 \pm 0,11^{\mathrm{a}, \mathrm{b}, \mathrm{c}, \mathrm{d}, \mathrm{e}}$ & $0,65 \pm 0,11^{a, b, c, d, e, f}$ & \\
\hline Kumlama & $2,57 \pm 0,14^{\mathrm{a}, \mathrm{fg}, \mathrm{h}, \mathrm{l}}$ & $1,25 \pm 0,32^{\mathrm{a}, \mathrm{g}, \mathrm{h}, \mathrm{l}}$ & $\begin{array}{l}t=11,35 \\
p=0,001^{*}\end{array}$ \\
\hline Er:YAG Lazer & $2,80 \pm 0,33^{b, f, j, k, 1}$ & $2,03 \pm 0,18^{\mathrm{b}, \mathrm{g} . \mathrm{j}, \mathrm{k}}$ & $\begin{array}{l}t=17,8 \\
p=0,001^{*}\end{array}$ \\
\hline Nd:YAG Lazer & $0,99 \pm 0,15^{\mathrm{c}, \mathrm{g}, \mathrm{m}}$ & $0,79 \pm 0,06^{\mathrm{h}, \mathrm{l}, \mathrm{m}, \mathrm{n}}$ & $\begin{array}{l}t=4,59 \\
p=0,001^{*}\end{array}$ \\
\hline $\begin{array}{l}\text { Er:YAG Lazer+ } \\
\text { kumlama }\end{array}$ & $4,20 \pm 0,40^{\mathrm{d}, \mathrm{j}, \mathrm{n}, \mathrm{o}, \mathrm{p}}$ & $4,06 \pm 0,45^{\mathrm{cj,j,l,o,p,r}}$ & $\begin{array}{l}t=1,13 \\
p=0,286\end{array}$ \\
\hline $\begin{array}{l}\text { Nd:YAG Lazer } \\
\text { + kumlama }\end{array}$ & $2,76 \pm 0,21^{\mathrm{e}, \mathrm{m}, \mathrm{n}, \mathrm{r}, \mathrm{s}}$ & $1,09 \pm 0,14^{\mathrm{d}, o, \mathrm{~s}}$ & $\begin{array}{l}t=36,58 \\
p=0,001^{*}\end{array}$ \\
\hline İnce grenli frez & $0,75 \pm 0,13^{\mathrm{h}, \mathrm{k}, \mathrm{o}, \mathrm{r}}$ & $1,35 \pm 0,17^{\text {em,p.t }}$ & $\begin{array}{l}t=7,60 \\
p=0,001^{*}\end{array}$ \\
\hline \multirow[t]{3}{*}{ Kalın grenli frez } & $0,85 \pm 0,17^{1, \mathrm{l}, \mathrm{p}, \mathrm{s}}$ & $2,72 \pm 0,36^{\mathrm{f}, 1, \mathrm{k}, \mathrm{n}, \mathrm{r}, \mathrm{s}, \mathrm{t}}$ & $\begin{array}{l}t=13,15 \\
p=0,001^{*}\end{array}$ \\
\hline & $F=325,52$ & $F=234,47$ & \\
\hline & $p=0,001$ & $p=0,001$ & \\
\hline
\end{tabular}

*Yatay sütunlarda her bir grup arasındaki fark istatistiksel olarak önemlidir $(P<0,05)$.

**Dikey sütunlarda aynı küçük harfle gösterilen ortalamalar arasındaki fark Tukey testine göre istatistiksel olarak önemlidir $(P<0,05)$.

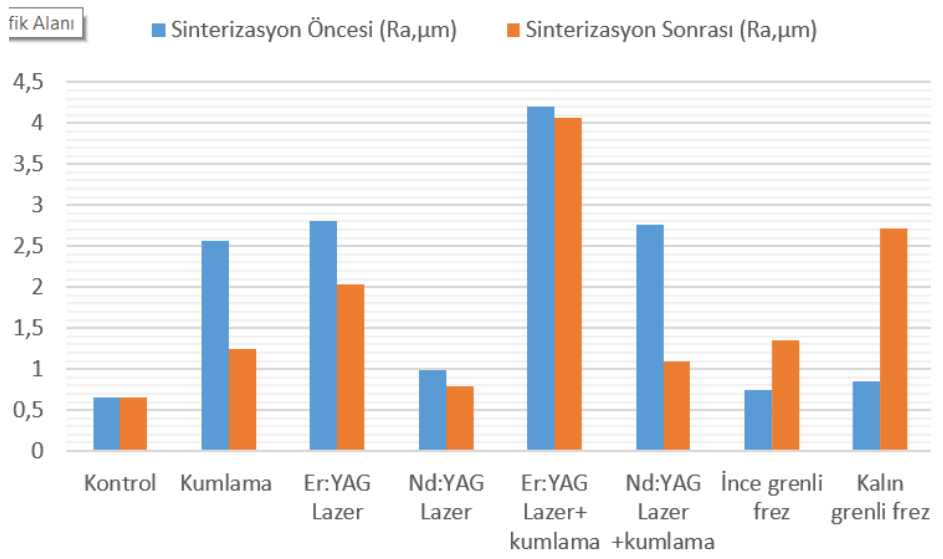

Şekil 1.

Yüzey pürüzlülük değerleri 


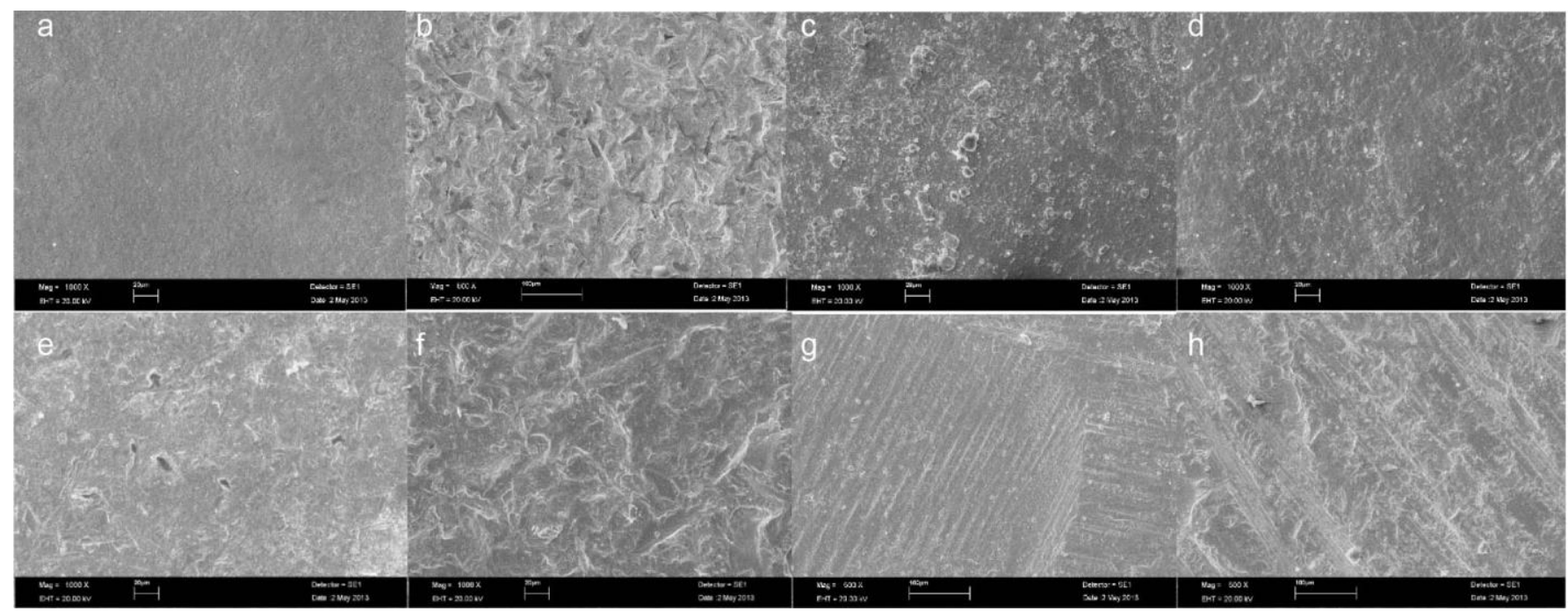

Resim 1.

Sinterizasyon öncesi yüzey işlemi uygulanıp sinterlenen örneklerin SEM görüntüleri (a- Kontrol, b-Kumlama, c-Nd-YAG lazer, d-Er-YAG lazer, e-NdYag+kumlama, f-Er-YAG+kumlama, g-İnce grenli frez, h-Kalın grenli frez)

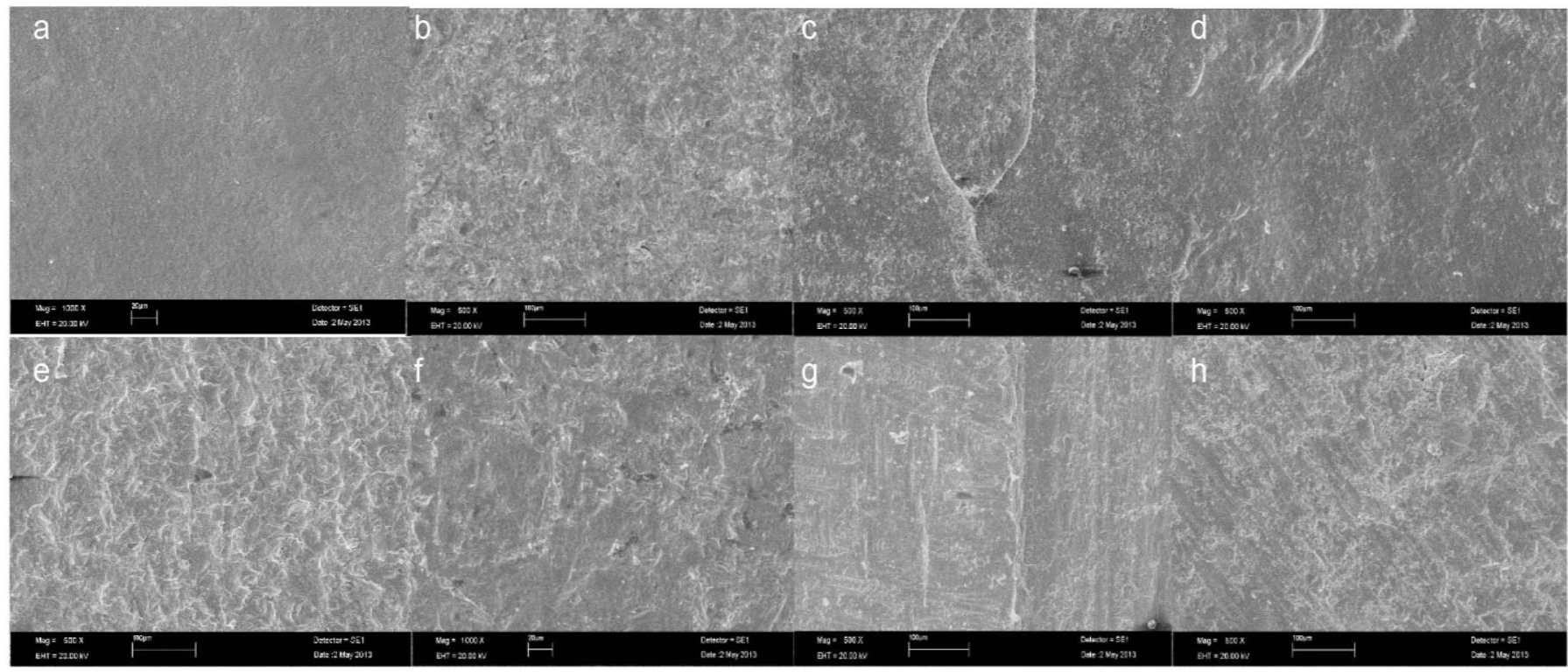

Resim 2.

Sinterizasyon sonrası yüzey işlemi uygulanan örneklerin SEM görüntüleri (a- Kontrol, b-Kumlama, c-Nd-YAG lazer, d-Er-YAG lazer, e-NdYag+kumlama, f-Er-YAG+kumlama, g-İnce grenli frez, h-Kalın grenli frez)

\section{TARTIŞMA}

Çalışma sonucunda elde edilen verilerin istatistiksel sonuçları çalışma hipotezini desteklemektedir. Sonuçlara göre sinterizasyon öncesi ve sinterizasyon sonrası uygulanan tüm yüzey işlemleri yüzey pürüzlülüğünü arttırdığı görülmüştür.

Yüzey pürüzlülüğü zirkonya seramiklerde mikromekanik bağlanma elde etmek için önemlidir. Adeziv sistemin gelişmesiyle bir çok araştırmacı $\mathrm{ZrO}_{2}$ yüzeyinde mikro tutucu alan elde etmek, yüzey alanını artırmak için farkı yüzey işlemleri denemişlerdir. 4,6,21,22 Yüzey alanlarının artması zirkonya ile porselen arasındaki bağlantıyı artırdığı belirtilmiştir. ${ }^{16}$ Bazı çalışmalar sinterizasyon sonrası yapılan yüzey işlemlerinde zirkonyum oksitte mikro çatlaklara sebebiyet verdiğini ve kırılma direncini azalttığını söylemişlerdir. ${ }^{23-24}$ Çalışmamızda bu sebeple sinterizasyon öncesi ve sonrası yüzey işlemleri uygulayıp farklarını araştırmayı amaçladık.

$\mathrm{Al}_{2} \mathrm{O}_{3}$ ile kumlama, yüzey alanını arttırarak vener seramiklerin bağlantısını arttıran önemli uygulama yöntemidir. Çalışmaların çoğu kumlamanın yapıştırma ajanına bakılmaksızın kron retansiyonunu arttırdığını belirtmişlerdir. Ayrıca mekanik özelliklerini de uzun dönemde olumlu yönde değiştirdiğini belirtmişlerdir. ${ }^{25,26}$ 
$\mathrm{ZrO}_{2}$ yüzeyinde çeşitli partikül boyutlarında $\mathrm{Al}_{2} \mathrm{O}_{3}$ ile kumlanmış çalışmalarda pürüzlülük değerlerini ve bağlanmayı arttırdığı belirtilmiştir. ${ }^{15,20,27}$ Oliveria ve ark. 120 ve $250 \mu \mathrm{m} \mathrm{Al}_{2} \mathrm{O}_{3}$ ile kumlamada partikül boyutu artışı ile yüzey pürüzlülük değerlerinde artış olduğunu belirtmişlerdir. ${ }^{28}$ Monaco ve ark. ${ }^{27} 110 \mu \mathrm{m} \mathrm{Al}_{2} \mathrm{O}_{3}$ en fazla pürüzlülük sağladığını, Yamaguchi' ${ }^{29}$ ve ark. $110 \mu \mathrm{m}$ $\mathrm{Al}_{2} \mathrm{O}_{3}$ 'ün $30 \quad \mu$ m'den daha fazla pürüzlülük oluşturduğunu, Kırmalı ve ark $120 \mu \mathrm{m} \mathrm{Al}_{2} \mathrm{O}_{3}$ 'ün lazer grupları ve işlem uygulanmamış zirkon grubuna göre daha fazla yüzey pürüzlülüğü oluşturduğunu belirtmişlerdir. ${ }^{20}$ Çalışmamızda da kullanılan $110 \mu \mathrm{m}$ $\mathrm{Al}_{2} \mathrm{O}_{3}$ 'ün sinterizasyon öncesi ve sonrasında pürüzlülüğü önemli derecede arttırdığı görüldüğünden çalışmalarla paralellik göstermiştir.

Aşındırma ve kumlamaya alternatif olarak zirkonya iç yüzeyine simantasyon öncesi reçine simanla olan bağlantıyı arttırmak amacıyla lazerle pürüzlendirmede yapılmıştır. Lazerle pürüzlendirmede zirkonya yüzeyine Er-YAG ya da Nd-YAG lazerle ablasyon yapılmaktadır. ${ }^{10,12,15,20,29}$

Cavalcanti ve ark. $^{9}$ da Er:YAG lazerin enerji yoğunluğunun artması ile yüzeyde oluşan çatlakların büyüdüğünü rapor etmişlerdir. Benzer şekilde, Akın ve ark. ${ }^{10}$ ise yaptıkları çalışmalarında, yüksek lazer enerji seviyelerinin zirkonyum oksitin yüzeyini bozduğunu ve çatlaklar meydana getirdiğini söylemişlerdir. Sunulan çalışmada bu sebeplerden dolayı lazer gruplarında düşük enerji seviyeleri kullanılmıştır. Turp ve ark. ${ }^{30}$ yaptıkları çalışmada farklı enerji yoğunluklarında $(100$, 200, 300 mj) Er_YAG lazer uygulamalarının kumlama işlemine göre pürüzlü yüzey elde ettiklerini ve düşük enerji yoğunluğunda daha etkili olduğunu belirtmişlerdir. Ayrıca Kırmalı ve ark. ${ }^{17}$ sinterizasyon öncesi $\mathrm{ZrO}_{2}$ ' nin yüzeyine Er-YAG ve Nd-YAG lazer ve bunların kumlama ile kombinasyonu şeklinde uygulamışlar. Er_YAG lazer ile kumlamanın birlikte uygulanması önemli derecede pürüzlülüğü arttırdığını belirtmişlerdir.

Demir ve ark. ${ }^{31}$ sinterlenmiş $\mathrm{ZrO}_{2}$ yüzeyine kumlama ve farklı enerji yoğunluklarında Er-YAG lazer uygulamışlar ve yüzey pürüzlülüğünü önemli derecede arttırdığını fakat istatistiksel olarak anlamlı olmadığını belirtmişlerdir. Cavalcanti ve ark. ${ }^{9}$ da $600 \mathrm{mj}$ enerji yoğunluğunda uygulanan Er-YAG lazerin kumlama ve diğer gruplara göre önemli derecede etkilediğini belirtmişlerdir. Benzer şekilde Subaşı ve ark. ${ }^{12}$ farklı yoğunlukta uygulanan lazerin yüzey pürüzlülüğünü arttırdığı ve SEM incelemesi sonucu yüzey topografisinde nadir pitlerin olduğunu rapor etmişlerdir. Çalışmamızda da Er-YAG lazer önemli derecede pürüzlülüğü arttırmıştır. Ancak bu yüzey etkinliği sinterizasyon öncesi grupta daha fazla olduğu görülmüştür. $\mathrm{Bu}$ durumu da $\mathrm{ZrO}_{2}{ }^{\prime}$ nin sinterizasyon öncesi daha kolay aşınmasına ve daha büyük yüzey düzensizlikleri meydana getirmesinden kaynaklandığını ve ayrıca SEM görüntülerinde tespit edilen yarık ve çukur yüzey özelliklerine de bağı olduğunu söyleyebiliriz.

Kırmalı ve ark. ${ }^{17}$ sinterlenmiş zirkonya üzerinde farklı yüzey işlemleri uygulamış ve en düşük yüzey pürüzlülük değerinin Nd-YAG lazer grubunda olduğunu ve kontrol grubuna göre fazla fark oluşturmadığını belirtmiştir. Çalışmamızda da Nd-YAG lazer grubu düşük pürüzlülük değeri göstermiştir. Akyıl ve ark. ${ }^{32}$ da zirkonyada çeşitli yüzey işlemleri uygulamış $\mathrm{Nd}$ :YAG lazer'in tek başına bağlanmayı azalttığı, Kumlama+Nd:YAG grubunda ise zirkonyum oksit ve rezin siman arasındaki bağlanmada artış olduğunu söylemişlerdir. Çalışmamızda da Nd-YAG lazer zirkonya yüzeyinde pürüzlülüğü arttırdığı istatistiksel olarak kontrol grubuna göre anlamlı olmasına rağmen diğer gruplara göre düşük değer bulunmuş ve kumlama ile beraber etkinliği daha da artmış olduğundan çalışmalara paralellik göstermiştir.

Frez ile aşındırma işlemlerinde yüzey pürüzlülüğünde önemli derecede artış sağlandığı fakat zirkonyanın mekanik özelliklerini azalttığına dair çok az çalışma mevcuttur. ${ }^{33}$ Çalışmamızda da sinterizasyon sonrası frez uygulamaları belirgin pürüzlülük değerinde artış göstererek yukarıdaki çalışmayı desteklerken, sinterizasyon öncesi uygulamalarında ise pürüzlülük değerlerin düşük çıkması çalışma ile uyuşmamaktadır. $\mathrm{Bu}$ durumu da, yüzey işleminden sonra $\mathrm{ZrO}_{2}{ }^{\prime}$ nin sinterlenmesi ile yüzeydeki girinti ve çatlakların sıkılaşmasından dolayı pürüzlülüğün azaldığını söyleyebiliriz. SEM görüntüleri ile de bu durum desteklenmektedir.

\section{SONUÇ}

Yüzey pürüzlülüğün artmasında kumlama haricinde alternatif olarak Er-Yag lazer ve kombinasyonuda kullanılabilir. $\mathrm{ZrO}_{2}{ }^{\prime}$ in pürüzlülük değerlerinin daha da artması ve mekanik özelliklerinin azalmaması için sinterizasyon öncesi işlemlerin yapılması ile bağlanma yönünden olumlu etki edebileceğini söyleyebiliriz. 


\section{KAYNAKLAR}

1. Anusavice KJ. Recent developments in restorative dental ceramics. J Am Dent Assoc 1993; 124: 72-84.

2. Manicone PF, Rossi lommetti P, Raffaelli L. An overview of zirconia ceramics: basic properties and clinical applications. J. Dent. 2007; 35: 819-26.

3. Luthardt RG, Holzhüter MS, Rudolph $\mathrm{H}$, Herold $\mathrm{V}$ and Water $\mathrm{MH}$. CAD/CAM-machining effects on Y-TZP zirconia. Dent Mater. 2004; 20: 655-62.

4. Kirmali O, Akin $\mathrm{H}$ and Ozdemir AK. Shear bond strength of veneering ceramic to zirconia core after different surface treatments. Photomed Laser Surg. 2013; 6: 261-8.

5. Sailer I, Feher A, Filser F, Gauckler LJ. Five-year clinical results of zirconia frameworks for posterior fixed partial dentures. Int J Prosthodont 2007; 20: 383-8.

6. Kim HJ, Lim HP, Park YJ, and Vang MS. Effect of zirconia surface treatments on the shear bond strength of veneering ceramic. J. Prosthet. Dent. 2011; 105: 315-22.

7. Smith RL, Villanueva C, Rothrock JK, Garcia-Godoy CE, Stoner BR, Piascik JR. Long-term microtensile bond strength of surface modified zirconia. Dent Mater 2011; 27: 779-85.

8. Kern M, Wegner SM. Bonding to zirconia ceramic: adhesion methods and their durability. Dent Mater 1998; 14: 64-71.

9. Cavalcanti AN, Foxton RM, Watson TF, Oliveira MT, Giannini M, Marchi GM. Bond strength of resin cements to a zirconia ceramic with different surface treatments. Oper Dent 2009; 34: 280-7.

10.Akin H, Ozkurt Z, Kirmali O, Kazazoglu E, Ozdemir AK. Shear bond strength of resin cement to zirconia ceramic after aluminum oxide sandblasting and various laser treatments. Photomed Laser Surg 2011; 29: 797-802.

11. Guess PC, Zhang Y, Kim JW, Rekow ED, Thompson VP. Damage and reliability of Y-TZP after cementation surface treatment. J Dent Res. 2010; 89: 592-6.

12.Subasi MG, Inan O. Evaluation of the topographical surface changes and roughness of zirconia after different surface treatments. Lasers Med Sci 2012; 27: 735-42.

13. Miyazaki T, Nakamura T, Matsumura H, Ban S, Kobayashi T. Current status of zirconia restoration. J Prosthodont Res 2013; 57: 236-61.

14.Dilber E, Yavuz T, Kara HB, and Ozturk AN. Comparison of the effects of surface treatments on roughness of two ceramic systems. Photomed. Laser Surg. 2012; 30: 308-14.

15. Akin H, Tugut F, Akin GE, Guney U, and Mutaf B. Effect of Er:YAG laser application on the shear bond strength and microleakage between resin cements and Y-TZP ceramics. Lasers Med. Sci. 2012; 27: 333-8.
16. Shiu P, De Souza-Zaroni WC, Eduardo CP, Youssef MN Effect of feldspathic ceramic surface treatments on bond strength to resin cement. Photomed Laser Surg 2007; 25: 291-6.

17. Kirmali O, Akin H, Kapdan A. Evaluation of the surface roughness of zirconia ceramics after different surface treatments. Acta Odontol Scand 2014; 72: 432-9.

18.Guess PC, Zhang Y, Kim JW, Rekow ED, Thompson VP. Damage and reliability of Y-TZP after cementation surface treatment. J Dent Res 2010; 89: 592-6

19. Moon JE, Kim SH, Lee JB, Ha SR, Choi YS. The effect of preparation order on the crystal structure of yttria-stabilized tetragonal zirconia polycrystal and the shear bond strength of dental resin cements. Dent Mater. 2011; 27: 651-63.

20.Kirmali O, Kustarci A, Kapdan A. Surface roughness and morphologic changes of zirconia: Effect of different surface treatment. Niger J Clin Pract. 2015; 18: 124-129

21.Aboushelib MN, Kleverlaan CJ, and Feilzer AJ. Effect of zirconia type on its bond strength with different veneer ceramics. J. Prosthodont 2008; 17: 401-8.

22. Fischer J, Grohmann P, and Stawarczyk B. Effect of zirconia surface treatments on the shear strength of zirconia/ veneering ceramic composites. Dent. Mater. J. 2008; 27: 448-54.

23. Guess PC, Zhang Y, Kim JW, Rekow ED, Thompson VP. Damage andreliability of Y-TZP after cementation surface treatment. J Dent Res 2010; 89: 592-6.

24.Kosmac T, Oblak C, Jevnikar P, Funduk N, Marion $\mathrm{L}$. The effect of surfacegrinding and sandblasting on flexural strength and reliability of Y-TZP zirconia ceramic. Dent Mater 1999;15: 426-33.

25. Guazzato M, Albakry M, Quach L, and Swain MV. Influence of surface and heat treatments on the flexural strength of a glass-infiltrated alumina/zirconiareinforced dental ceramic. Dent. Mater. 2005;21: 454-63.

26. Uo M, Sjogren G, Sundh A, Goto M, Watari F, and Bergman M. Effect of surface condition of dental zirconia ceramic (Denzir) on bonding. Dent. Mater. J. 2006; 25: 626-31

27. Monaco C, Cardelli P, Scotti R, Valandro LF. Pilot evaluation of four experimental conditioning treatments to improve the bond strength between resin cement and Y-TZP ceramic. $J$ Prosthodont 2011; 20: 97-100. 
28.Abi-Rached FO, Martins SB, Campos JA, Fonseca RG. Evaluation of roughness, wettability, and morphology of an yttria-stabilized tetragonal zirconia polycrystal ceramic after different airborne-particle abrasion protocols J Prosthet Dent 2014; 112: 1385-91

29. Yamaguchi H, Ino S, Hamano N, Okada S, Teranaka $\mathrm{T}$. Examination of bond strength and mechanical properties of Y-TZP zirconia ceramics with different surface modifications. Dent Mater J 2012; 31: 472-80

30.Turp V, Akgungor G, Sen D, Tuncelli B. Evaluation of Surface Topography of Zirconia Ceramic After Er:YAG Laser Etching. Photomed Laser Surg 2014; 32: 533-9

31.Demir N, Subası G, Ozturk N. Surface Roughness and Morphologic Changes of Zirconia Following Different Surface Treatments. Photomed Laser Surg 2012; 30: 339-45

32.Akyil MS, Uzun iH, Bayindir F. Bond strength of resin cement to yttrium-stabilized tetragonal zirconia ceramic treated with air abrasion, silica coating, and laser irradiation. Photomed Laser Surg 2010; 28: 801. 8.

33.Prado RD, Rocha Pereıra GK, Bottıno MA, De Melo RM, Valandro LF. Effect of ceramic thickness, grinding,and aging on the mechanical behavior of a polycrystalline zirconia. Braz Oral Res 2017; 31: 1-9.

\section{Yazışma Adresi:}

Doç. Dr. Faik TUĞUT

Cumhuriyet Üniversitesi Diş Hekimliği Fakültesi

Protetik Diş Tedavisi AD

58140, Sivas

Tel : : +903462191010/2758

Faks : +903462191237

E Posta: tugut78@hotmail.com 